\title{
Spatiotemporal variability of land surface moisture based on vegetation and temperature characteristics in Northern Shaanxi Loess Plateau, China
}

\author{
Zhengguo Li ${ }^{\mathrm{a}, \mathrm{b}}$, Yanglin Wang ${ }^{\mathrm{a}, *}$, Qingbo Zhou ${ }^{\mathrm{b}}$, Jiansheng $\mathrm{Wu}^{\mathrm{c}}$, \\ Jian Peng ${ }^{\mathrm{a}}$, Hsiaofei Chang ${ }^{\mathrm{d}}$ \\ ${ }^{a}$ Department of Geography, Peking University, Beijing 100871, China \\ ${ }^{\mathrm{b}}$ Key Laboratory of Resources Remote sensing and Digital Agriculture, Ministry of Agriculture (MOA), Beijing 100081, China \\ ${ }^{\mathrm{c}}$ Shenzhen Graduate School, Peking University, Shenzhen 518031, China \\ ${ }^{\mathrm{d}}$ Research Center for Eco-Environmental Sciences, Chinese Academy of Sciences, P.O. Box 2871, Beijing 100085, China
}

Received 9 July 2007; received in revised form 19 October 2007; accepted 24 November 2007

Available online 31 January 2008

\begin{abstract}
Vegetation coverage and surface temperature are important parameters in describing the characteristics of land cover, which in combination can provide information on vegetation and soil moisture conditions at the surface. This paper aims to estimate spatial and temporal patterns of soil moisture in the Loess Plateau, China. Using Terra/MODIS images for each 10-day period in 2004 covering the semi-arid North Shaanxi Loess Plateau, a simplified land surface dryness index (Temperature-Vegetation Dryness Index, TVDI) developed by Sandholt [Sandholt, I., Rasmussena, K, Andersenb, J., 2002. A simple interpretation of the surface temperature/vegetation index space for assessment of surface moisture status. Remote Sensing of Environment 79, 213-224.] was used to determine the relationship between surface temperature and vegetation index. From the analysis, it can be inferred that the trend in seasonal change of TVDI is high values in the dry season (spring or summer) and low values in the rainy season (autumn or winter). Moreover, the land surface moisture of each watershed had its seasonal characteristics. The relationship between TVDI and land cover types indicated that waterretention in forest and shrub areas was better than cropland and rangeland in relatively wet conditions, and rangeland was better than forest and shrub areas in dry conditions.
\end{abstract}

(C) 2007 Elsevier Ltd. All rights reserved.

Keywords: NDVI; Land surface temperature; TVDI; MODIS

\section{Introduction}

Land surface parameters, such as land cover, land surface temperature (LST) and land surface moisture (LSM), are important parameters in the physics of land surface processes on a regional and global scale, combining all surface-atmosphere interaction and energy fluxes (Fu et al., 1999; Mannstein, 1987; Ran et al.,

\footnotetext{
*Corresponding author. Tel.: + 861062759374 ; fax: + 861062751187 .

E-mail addresses: lzg.123@263.net (Z. Li), ylwang@urban.pku.edu.cn (Y. Wang).
} 
2005; Sellers et al., 1988; Yao et al., 2004). One of the most important potential applications of LSM assessment is to provide information for agriculture on water stress for irrigation decisions and yield estimation (Penuelas et al., 1993). LSM can also be used to determine fire susceptibility of forests (Pyne et al., 1996). Spatially distributed LSM estimation is usually based on interpolation of field data or modelling of environmental factors, such as climate, topography, land use, soil and vegetation (Friedl and Davis, 1994; Fu et al., 2000; Wang et al., 2003). Remotely sensed data has great potential in the retrieval of LSM spatiotemporal variability. The increasing availability of remotely sensed data at various spatial, temporal, and spectral resolutions offers the potential to monitor and retrieve biophysical characteristics of ecological systems, such as LSM and LST (Lambin and Ehrlich, 1996; Liu and Kogan, 1996; McVicar and Jupp, 1998).

A variety of LSM retrieval methods using remotely sensed data have been published. Here, we provide some examples rather than a complete review. Based on the correlations of vegetation water content with the biomass, Normalized Difference Vegetation Index (NDVI) images, generated from NOAA AVHRR GVI (Global Vegetation Index) data, have been used to monitor large-scale water stress and its impact on vegetation (Jackson and Schmugge, 1991; Kogan, 1995; Tian, 1993; Tucker, 1979). However, NDVI is, in fact, often referred to as a greenness index rather than a moisture index (Jackson et al., 2004). Combined with LST characteristics, Gao (1996) developed the Normalized Difference Water Index from a near infrared channel and a short wave infrared wavelength channel. To evaluate LSM status based on physical principles, Jackson et al. (1981) developed the Crop Water Stress Index (CWSI), expressed as a function of canopy and air temperatures. On the assumption that LSM is a linear function of canopy temperature and vegetation cover fraction, the Water Deficit Index (WDI) was developed from CWSI by Moran et al. (1994), and is related to the actual and potential surface evapotranspiration rates. Recently, a simplified land surface dryness index (Temperature-Vegetation Dryness Index, TVDI) based on an empirical parameterisation of the relationship between LST and NDVI was developed (Sandholt et al., 2002; Wan et al., 2004); this index integrates land surface reflection and thermal properties. In comparison to existing interpretations of the LST/NDVI space, the index is conceptually and computationally straightforward (Sandholt et al., 2002).

Remotely sensed data from the Moderate Resolution Imaging Spectroradiometer (MODIS) offers an improvement in monitoring ecosystem characteristics on regional to global scales (Justice et al., 1998; Townshend and Justice, 2002). The present paper aims at demonstrating how Terra/MODIS data may be used to estimate spatial and temporal change of LSM and examine drought conditions in the Loess Plateau, China. Land cover, an alternative attribute that is easily obtained, also plays an important role in controlling spatial patterns of LSM by influencing the infiltration, runoff and evapotranspiration, particularly during the growth season (Francis et al., 1986; Fu and Chen, 2000; Fu and Gulinck, 1994; Fu et al., 2000; Hawley et al., 1983; Ng and Miller, 1980; Reynolds, 1970). To understand the relationship between land cover types and TVDI in the Loess Plateau, TVDI was grouped into different classes according to spatiotemporal distribution characteristics, i.e., mean and variance of TVDI monthly, and land cover composition, such as cropland, forest, shrub, and rangeland.

\section{Study area and data source}

The study area includes the northern part of Shaanxi Province, China between $107^{\circ} 28^{\prime} \mathrm{E}-111^{\circ} 15^{\prime} \mathrm{E}$ and $35^{\circ} 21^{\prime} \mathrm{N}-39^{\circ} 34^{\prime} \mathrm{N}$, located in the middle part of the Loess Plateau and separated from the Yellow River. The area covers $80,606 \mathrm{~km}^{2}$ and the elevation is $400-1900 \mathrm{~m}$ (Fig. 1), and the main watersheds include the Kuye, Wuding, Qingqian, Yan, Fenchuan Rivers and part of the Luo River (Fig. 1). The terrain has significant topographic variability with typical Loess hills and gully slope shapes. The area has a semi-arid continental monsoon climate characterized by cold winters, and warm summers. The average annual temperature (AAT) is $6.5^{\circ} \mathrm{C}$ or less in the northwest and increases to $12.5^{\circ} \mathrm{C}$ in the southeast. The average annual precipitation (AAP) is $>600 \mathrm{~mm}$ in the south and gradually decreases northward to $250 \mathrm{~mm}(\mathrm{Fu}, 1995)$. The inter-annual variability of precipitation is as high as $40 \%$; the rainy season is short, as $>60 \%$ of rainfall is in July-September; and $>50 \%$ of the precipitation occurs during storms (Fu, 1995; Fu et al., 1999). The hilly topography, intensive precipitation, and especially long-term extensive human activity (i.e., removal of the natural vegetation and farming-accelerated deterioration), have caused serious soil erosion. Most of the natural forest vegetation has been cleared and the current vegetation is primarily native and introduced 


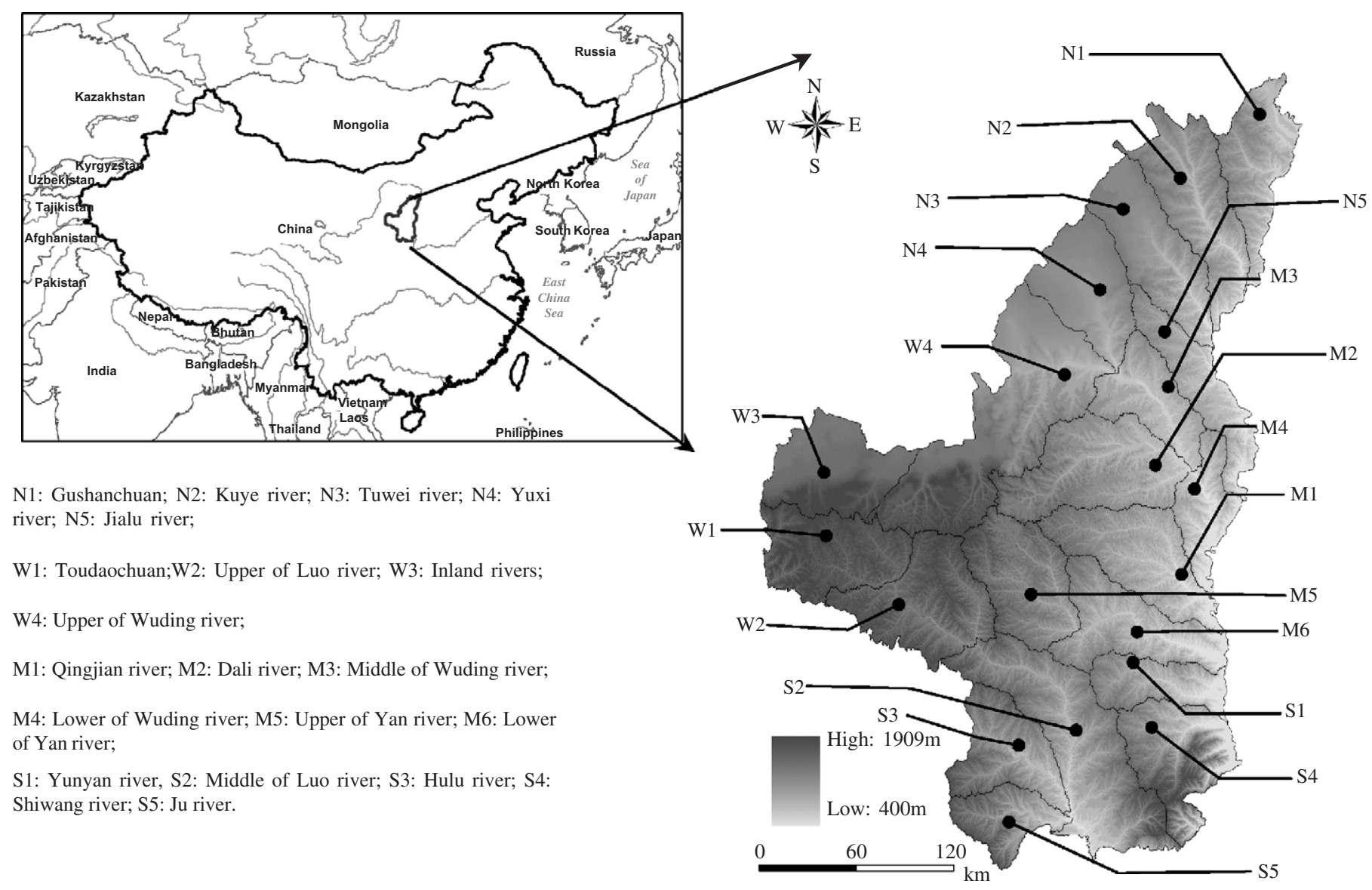

Fig. 1. Geographical location of study area and delineation of watersheds. 
Table 1

Data source

\begin{tabular}{|c|c|}
\hline Data source & Date/resolution \\
\hline \multicolumn{2}{|l|}{ TM images } \\
\hline $126-33 / 34 / 35 / 36$ & 9 June 2004 , with a resolution of $30 \mathrm{~m}$ \\
\hline $127-33 / 34 / 35$ & 16 June 2004 , with a resolution of $30 \mathrm{~m}$ \\
\hline $128-34 / 35$ & 7 June 2004 , with a resolution of $30 \mathrm{~m}$ \\
\hline \multicolumn{2}{|l|}{ MODIS images } \\
\hline LST products (MOD11) & 10-day composite in 2004 , with a resolution of $1 \mathrm{~km}$ \\
\hline VI products (MOD13) & 10-day composite in 2004 , with a resolution of $0.5 \mathrm{~km}$ \\
\hline Topographic map of Shaanxi province $(1: 50,000)$ & Published in 2000 by National Geomatics Center of China \\
\hline Land use map of Shaanxi province & $\begin{array}{l}\text { Made in } 2000 \text { by Institute of Geographical Sciences and Natural } \\
\text { Resources Research, Chinese Academy of Sciences }\end{array}$ \\
\hline
\end{tabular}

grasses. The present land cover and vegetation types include cropland, shrub, forest (mainly in south mountainous area) and rangeland. Crops are mainly potatoes (Solanum tuberosum), beans (Phaseolus vulgaris), maize (Zea mays) and millet (Panicum miliaceum). The forest is dominated by introduced vegetation, mainly locust trees (Robinia pseudoacacia). In this area, littleleaf peashrub (Caragana microphylla) is the most important of the shrub species. The rangeland is mainly covered by annuals such as wheatgrass (Agropyron cristatum Gaertn.), sweet wormwood (Artemisia annua), annual fleabane (Erigeron annuus) and sandy needlegrass (Stipa glareosa).

Data sources are listed in Table 1. Landsat data acquired on 7, 9 and 16 June 2004 were used to map land cover in the study area. MODIS 10-day VI and LST composite products in the period 2004-2005 were applied in the analyses that follow. Due to limited availability of validated Landsat data coinciding with MODIS collects, our analysis was limited to 2004-2005 and to the major land cover types. These data sets provided a means to assess MODIS estimates of LSM at regional spatial scale.

\section{Methodology}

\subsection{Data processing}

Data preprocessing was performed with remotely sensed image processing software packages - ENVI 4.0, developed by RSI Company, and the geographical information system software ARC/GIS 9.0, by ESRI Company.

Prior to analysis, following atmospheric radiance calibration and initial geometric rectification of all the TM images using ENVI, a number of reference points were selected from a scale of 1:50,000 topographic map, and the TM images were rectified to a Gauss Kruger projection with a pixel resolution of $30 \mathrm{~m} \times 30 \mathrm{~m}$ by using nearest neighbour rules provided by ENVI, to ensure that the error was controlled in less than one-half pixel root mean square error. The MODIS products were also rectified to the Gauss Kruger projection by the above method, and resampled to $500 \mathrm{~m} \times 500 \mathrm{~m}$ pixel resolution. Finally, after the process of masking the data with the administrative edge, the analysis was limited to the administrative area of the northern Shaanxi Province.

Land cover classification was obtained with a supervised procedure using a maximum likelihood algorithm in ENVI. The main classes were forest, shrub, rangeland, cropland and water. To check the accuracy of the map, the layer with the field-checked sites was overlaid on the corrected satellite images, and the resulting Kappa coefficient was 0.79 , which was satisfactory.

MODIS VI and LST 10-day composite products were obtained for the period 2004-2005. The VI product (MOD13) includes maximum value composites (MVC) of the normalized difference VI (NDVI) and enhanced VI (EVI), as well as the corresponding red and near-infrared (NIR) reflectance (bands 1 and 2) and quality assessment (QA) flags (Huete et al., 2002). LST product (MOD11) includes MVC of the daily result of the 
generalized split-window algorithm, emissivities in bands 31 and 32, error in LST and QA flags. For this study, we used only NDVI and LST values from the MODIS composite products, along with the VI and LST Usefulness Index in the QA data set. Reflectance values of NDVI and LST for dates with a Usefulness Index value lower than "good quality" were replaced by linearly interpolated values from the two closest dates with good, high, or perfect quality.

\subsection{Temperature-vegetation dryness index, TVDI}

The LST/NDVI slope is related to the surface evapotranspiration rate, and has been used to estimate air temperature (Boegh et al., 1998; Prihodko and Goward, 1997). Analysis of the LST/NDVI slope can be used to assess information related to real averaged soil moisture conditions (Goetz, 1997; Goward et al., 2002). Isolines can be drawn in the triangle defining the LST/NDVI space (Sandholt et al., 2002).

As a first iteration to obtain information on the surface soil moisture content, TVDI is defined as the ratio of LST differences between pixels with a specific NDVI value in a sufficiently large study area. TVDI can be defined:

$$
\mathrm{TVDI}=\frac{\mathrm{LST}-\mathrm{LST}_{\min }}{a+b \mathrm{NDVI}-\mathrm{LST}_{\min }}
$$

where $\mathrm{LST}_{\min }$ is the minimum surface temperature in the triangle, defining the "wet edge" (maximum evapotranspiration and thereby unlimited water access), LST is the observed surface temperature at the given pixel, NDVI is the observed normalized difference vegetation index, and $a$ and $b$ are parameters defining the "dry edge" (limited water availability), which is modelled as a linear fit to data $\left(\mathrm{LST}_{\max }=\right.$ $a+[b \times \mathrm{NDVI}]$ ), where $\mathrm{LST}_{\max }$ is the maximum surface temperature observation for a given NDVI (Sandholt et al., 2002). TVDI is lower for wet and higher for dry conditions, with values of 1 at the "dry edge" and 0 at the "wet edge". The uncertainty of TVDI is larger for high NDVI values, where the TVDI isolines are closely set.

\subsection{Moisture index (IM)}

IM was developed by Thornthwaite (1948) and is a climatic classification measure of precipitation effectiveness for plant growth. IM allows for the weighted influence of water surplus and deficiency, which can infer the proportion of total precipitation used to satisfy vegetation needs. For a given station, IM is calculated by the formula:

$$
\mathrm{IM}=\sum \frac{100 \times(S-0.6 D)}{\mathrm{PE}},
$$

where $S$ is the water surplus, being the total surplus from all months having a water surplus; $D$ is the water deficiency, being the total of all monthly deficiencies; and PE is the annual potential evapotranspiration. The calculations of $S$ and $D$ are on a normal month-to-month basis; each is represented by the difference between monthly precipitation and monthly potential evapotranspiration (in $\mathrm{cm}$ ).

The general approach used in this investigation is as follows. Linear regression functions at monthly intervals were developed to determine the parameters describing the "dry edge". Using these parameters, TVDI was calculated to evaluate spatial and temporal variability of drought based on the Terra/MODIS NDVI and LST products. Finally, drought conditions of each land cover type were assessed.

\section{Results}

\section{1. $L S T_{\max }$ and NDVI temporal relationships}

Steeper LST/NDVI slopes indicate drier conditions (Goetz, 1997; Nemani and Running, 1989). The parameters $a$ and $b$ describing the "dry edge" were estimated on the basis of pixels from an area large enough 
to represent the range of surface moisture contents, and from bare soil to fully vegetated surfaces. In order to determine the parameters, $\mathrm{LST}_{\max }$ observed for small intervals of NDVI was extracted in the LST/NDVI space (Fig. 2), and the parameters were found using least square linear regression on the sloping side of the "dry edge".

Plots of $\mathrm{LST}_{\max }$ as a function of NDVI for each image illustrated the seasonal variability of the parameters (Fig. 2). Winter (January) was characterized by low NDVI values and low $\mathrm{LST}_{\max }$, and a positive relationship with a correlation coefficient $\left(r^{2}>0.83\right)$ and slope $(b) \sim 0.16$. The relationship showed that in winter LST was higher in the areas with more vegetation. From January to April, LST $_{\max }$ increased, however, NDVI remained almost unchanged, so $b$ decreased to 0.06 . There was no significant correlation $\left(r^{2} \sim 0.19\right)$ between the individual TVDI parameters, indicating that LST was similar for bare soil and vegetated areas. In July, all plants were growing rapidly. There was a negative relationship between $\mathrm{LST}_{\max }$ and NDVI, with $b \sim-0.21$ and $r^{2}>0.94$. The relationship showed that LST was higher for bare soil in summer. In October, both LST max and NDVI had decreased. The relationship was weakly positive, $b \sim 0.07$ and $r^{2} \sim 0.35$, which indicated little spatial variability in LST during autumn.

Apparent random variation is evident in the seasonal variation of the TVDI parameters, in accordance with Sandholt et al. (2002). The lack of correlation and distinct trends in the parameters may be due to several factors, including highly variable atmospheric forcing. Other studies have reported similar behaviours of seasonal variation in slope (Goetz, 1997; Prihodko and Goward, 1997).

a

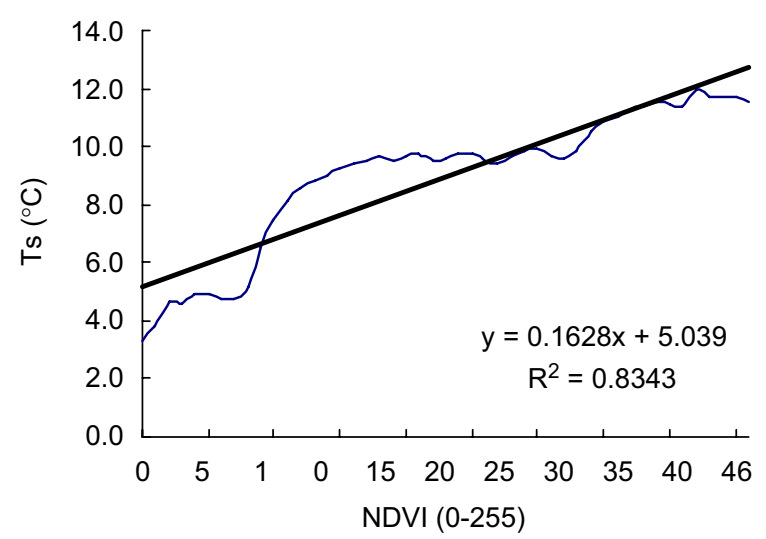

C

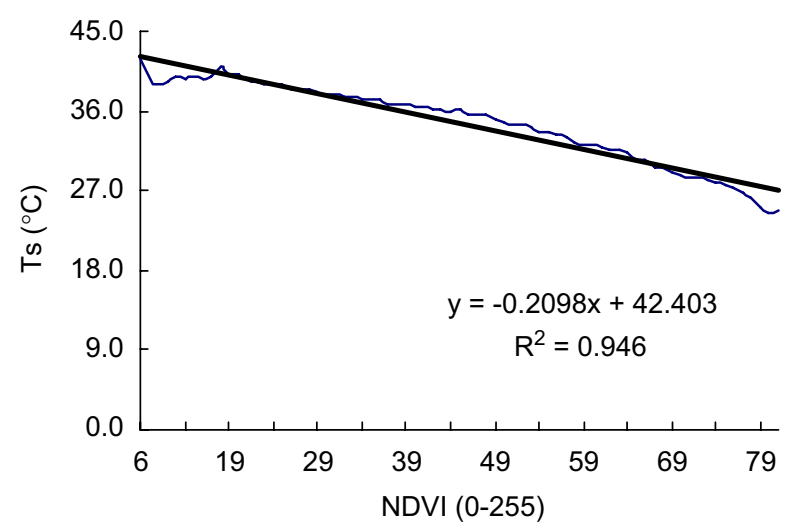

b

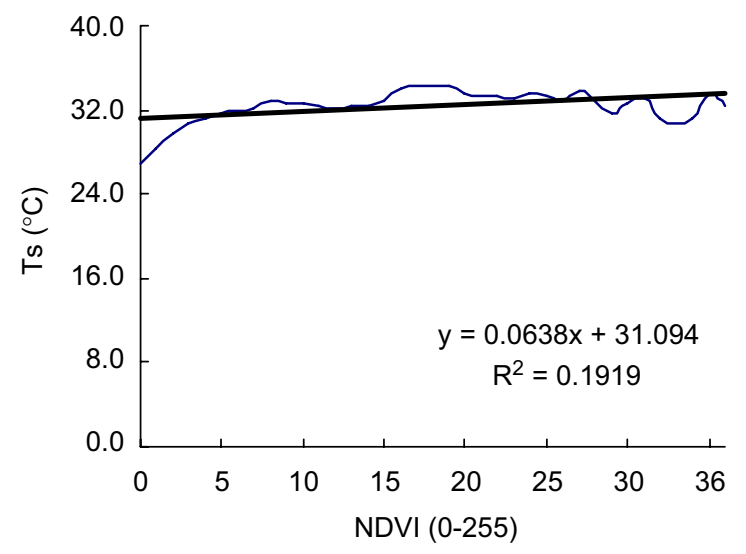

d

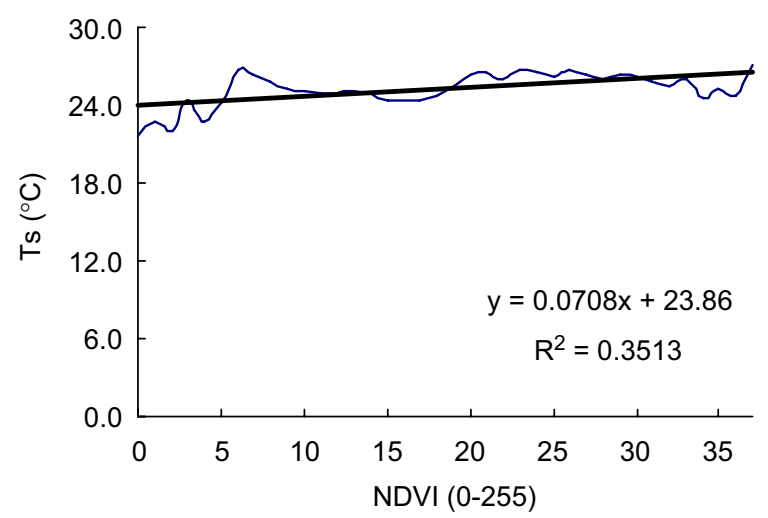

Fig. 2. Dry edge values used for estimation of TVDI. Maximum LST was extracted for small intervals of NDVI, and the dry edge was estimated by linear regression. 


\subsection{Temporal evolution of TVDI}

The spatial distribution of TVDI for January, April, July and October is shown in Fig. 3. There was seasonal variation in TVDI (Table 2). In January, TVDI in the study area was low with a mean $(m)$ of 0.27 and large spatial variation with a variance $(s)$ of 0.10 . In April, TVDI was generally higher $(m \sim 0.54)$ with little spatial variation $(s \sim 0.08)$. In July, probably due to the relatively high surface temperature of the
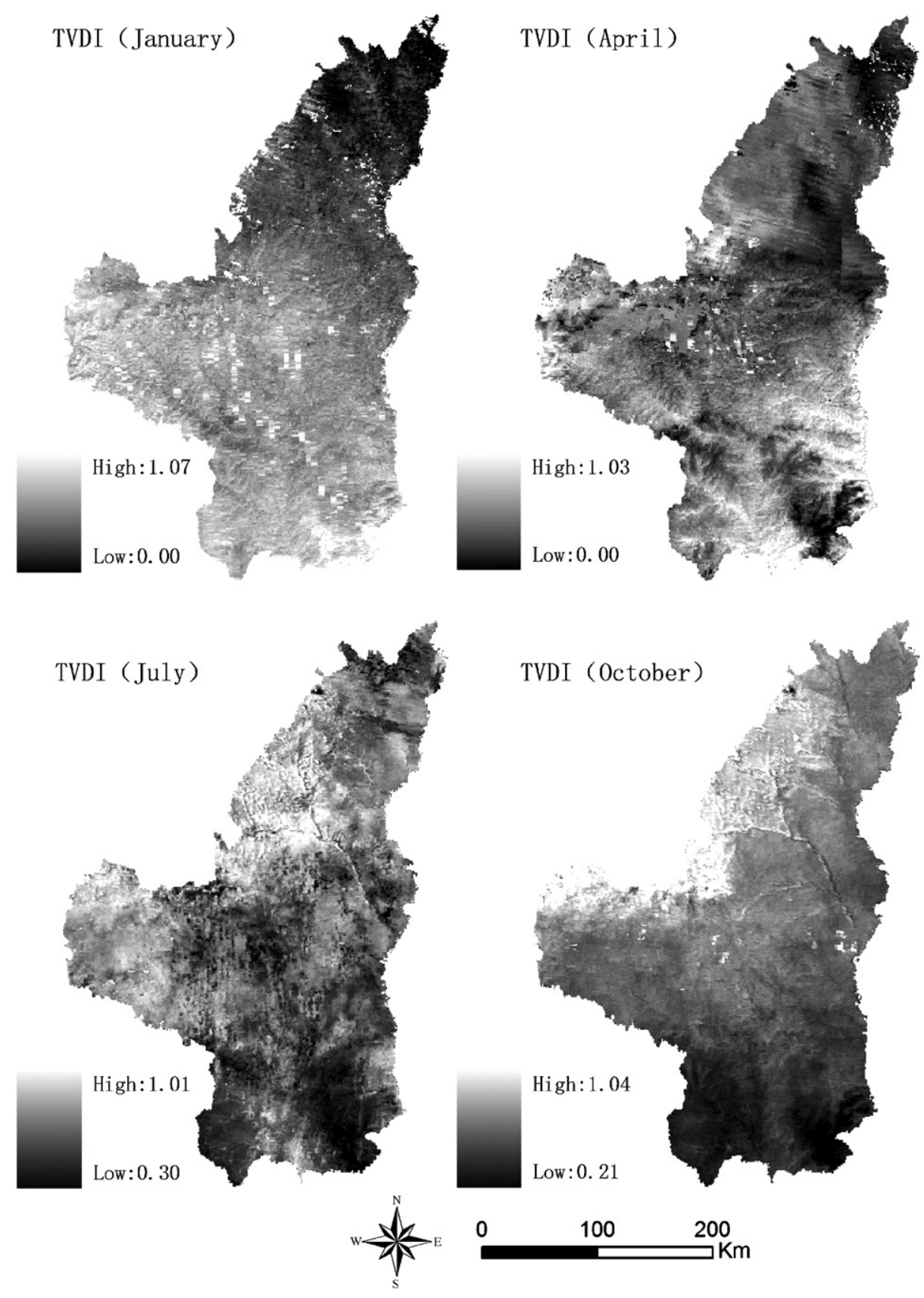

Fig. 3. TVDI for 4 months. The TVDI images are derived from maximum-value composite images from temporal Terra/MODIS data products. Bright areas correspond to dry conditions (high TVDI) and darker areas correspond to moister conditions (low TVDI). 
Table 2

Temporal evolution in TVDI statistics in Loess Plateau

\begin{tabular}{llllllllllllll}
\hline & January & February & March & April & May & June & July & August & September & October & November & December \\
\hline Mean & 0.27 & 0.28 & 0.51 & 0.54 & 0.56 & 0.70 & 0.75 & 0.41 & 0.46 & 0.29 & 0.42 & 0.32 \\
Variance & 0.10 & 0.07 & 0.06 & 0.08 & 0.18 & 0.15 & 0.19 & 0.12 & 0.07 & 0.13 & 0.06 & 0.08 \\
\hline
\end{tabular}

homogeneous cover type, TVDI was highest $(m \sim 0.75)$ with the largest spatial variation $(s \sim 0.18)$. In October, TVDI was lower $(m \sim 0.29)$ and had high spatial variation $(s \sim 0.13)$.

For areas covered by vegetation, LST is actually temperature of vegetation canopy. However, interpretation of surface temperature for sparse canopies is complicated, because the measured temperature integrates the temperature of both the bare soil surface and the vegetation (Friedl \& Davis, 1994; Sandholt et al. 2002). In the Loess Plateau area, when water is abundant, especially in rainy season, evaporation capacity of the vegetation canopy will be very large and canopy temperature is correspondingly low; and NDVI, which reflect the livingness of vegetation, will be large. Similarly, when vegetation cannot get enough water in the dry season, evaporation capacity of the vegetation canopy will be small and canopy temperature is high, and NDVI will be small. So, TVDI can indicate the regional condition of water and the vegetation capacity in absorbing water. Similar to other arid and semi-arid climates, the overall trend of TVDI in the Loess Plateau can be simplified as higher values and variability in the dry season and lower values in the rainy season.

\subsection{Spatiotemporal variation of TVDI in watersheds}

The spatiotemporal variation of TVDI in watersheds is shown in Appendix 1, electronic version. In the watersheds of the Loess Plateau area, in January, mean TVDI of northern watersheds was lowest $(m<0.20)$, however, TVDI in the southern watersheds was highest $(m>0.30)$, and there was little spatial variation with a variance $(s)$ of less than 0.10 for all the watersheds; In April, mean TVDI of all watersheds increased to more than 0.50 and there was little change in $s$; in July, mean TVDI increased further to $>0.65$ with $s$ still unchanged, except for the southern watersheds; But in October, mean TVDI in southern watersheds decreased to less than 0.25 , however, TVDI in the northern watersheds remained relatively high $(m \sim 0.30)$ and $s$ increased to 0.15 , which was higher than averages in the area.

The spatiotemporal variation of drought could be divided into two distinct periods. From March to September, the land surface was generally drier with large spatial variations, especially in the watersheds of the middle and western area. October-February was relatively wet with low mean TVDI $(<0.20)$ and little spatial variation, especially in the north.

\subsection{Comparing TVDI with moisture index}

In general, TVDI is sensitive to rainfall, and decreases after rain events (Gillies et al., 1997; Goward et al., 2002; Sandholt et al., 2002). Validation using field measurements is difficult at the scale of Terra/MODIS imagery, so assessment of the proposed methodology may be best compared to LSM status over large areas (Fig. 4a and b).

To illustrate drought condition differences in overall magnitude and differences in seasonal response, a classification based on temporal and spatial patterns of TVDI was performed. First, TVDI layers for each month in 2004 were subjected to a clustering procedure, followed by a supervised maximum likelihood classification in ENVI; second, classes were aggregated into 10 final groups using a dendrogram and relative distance statistics. Finally, the mean and variances were extracted for each TVDI class (Appendix 2, electronic version). From the southeast to the northwest, the mean TVDI increased from 0.18 to 0.75 and $s$ was $\sim 0.02$, which reflected the spatial trend of land surface drought conditions.

TVDI was compared with climatic factors; in the TVDI classes 1-3, the area with best LSM status, TVDI $<0.30, \mathrm{AAT}<5^{\circ} \mathrm{C}, \mathrm{AAP}>500 \mathrm{~mm}$ and $\mathrm{IM}>12$; in classes 4-6, TVDI increased to 0.35-0.47, 
a

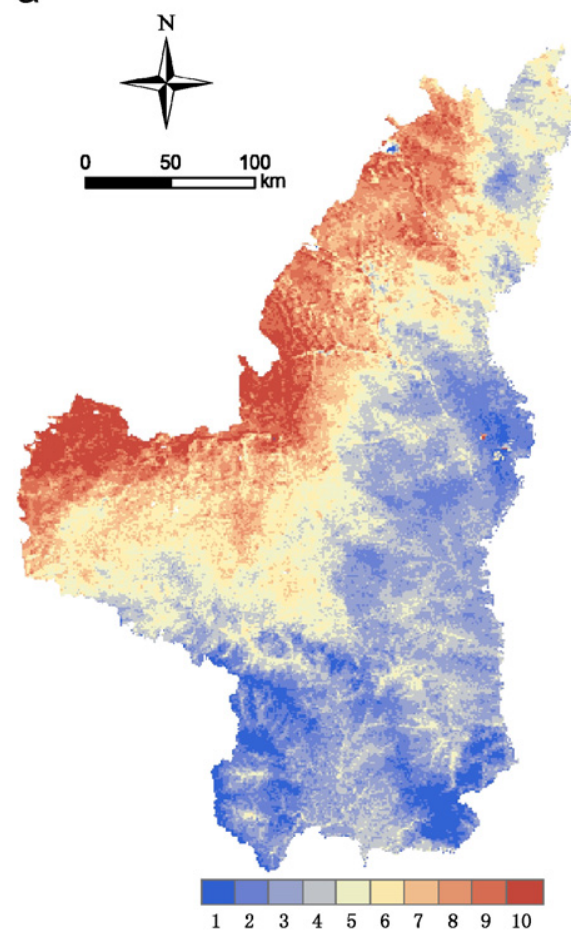

b

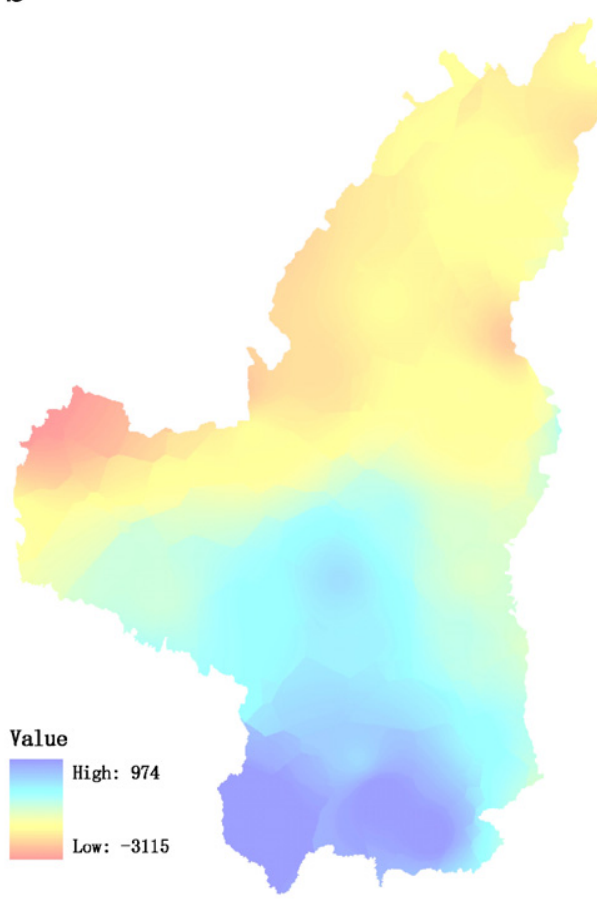

Fig. 4. Classification of TVDI and its validating factors.

correspondingly AAT rose to $6.12-7.41^{\circ} \mathrm{C}$, AAP was reduced to $<500 \mathrm{~mm}$, and IM decreased from -12 to -20 ; in classes $7-10$, TVDI continuously increased from $0.53-0.75$, correspondingly AAT rose to 8.19-12.03 ${ }^{\circ} \mathrm{C}$, AAP was reduced to $<410 \mathrm{~mm}$, and $\mathrm{IM}<-20$; In general, higher TVDI corresponded to higher AAT, lower AAP and IM values and vice versa. The patterns for the TVDI and IM were similar, showing the effectiveness of TVDI in describing the integrated effects of land temperature and precipitation on LSM.

\subsection{Composition of land cover types in TVDI class}

To understand the relationship between TVDI and land cover types in the Loess Plateau, we assessed the composition of land cover types in each TVDI class (Fig. 5). According to the classification results of TM images in 2004, the primary land cover types were cropland, forest, shrub, and rangeland. TVDI class 1 was mostly shrubs and grasses; in classes 2 and 3, forest, shrub and rangeland were low and cropland high; and from classes 4 to 10, the proportions of each land cover type were similar. It can be inferred that waterretention in forest and shrub areas was better than cropland and rangeland in relatively wet conditions, and rangeland was better than forest and shrub areas in dry conditions.

\section{Conclusions and discussions}

The present study was conducted on the northern Shaanxi Loess Plateau area, and analysed spatiotemporal characteristics of LSM with time series data of NDVI, LST and TVDI. The main results were (1) the combination of LST and NDVI will enhance the ability to derive moisture data without the utilization of time and resource intensive field work, which is especially important in the many areas of research that span more than small plots, but rather regional and global studies. In this paper, TVDI based on a different type of sensor (MODIS) than originally used in developing the index (NOAA-AVHRR) was suggested for monitoring 


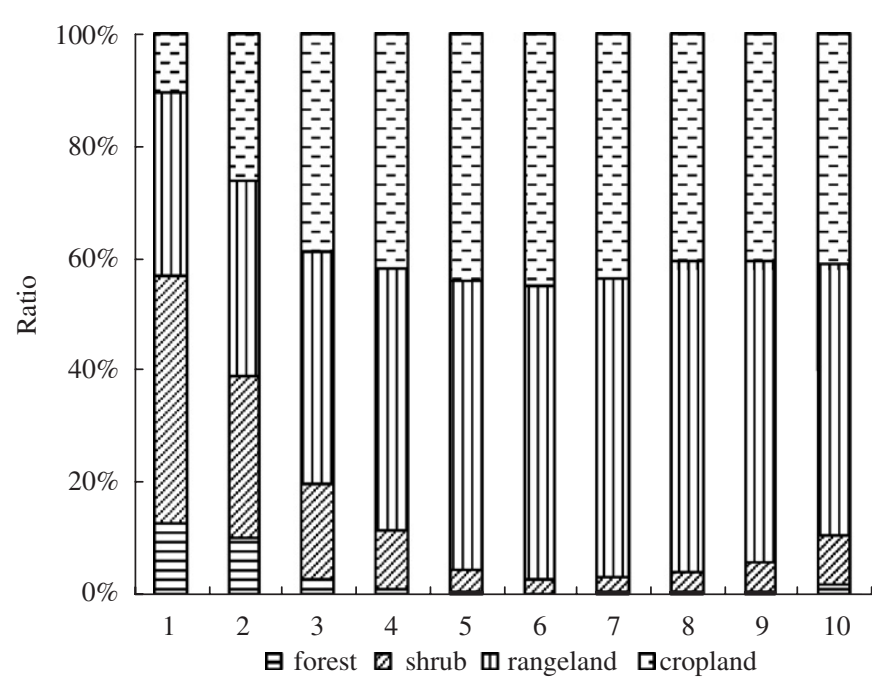

Fig. 5. Land covers composition in different TVDI class.

large scale LSM status, and tested in the Loess Plateau area. Estimation of the TVDI parameters was most problematic in the dry season, and there was no distinct trend in the seasonal variation of the parameters, in accordance with Sandholt et al. (2002). (2) Evaluated against IM, the effectiveness of TVDI in describing the integrated effects of land temperature and precipitation on LSM was demonstrated. (3) Seasonal variation in TVDI indicated that the trend in TVDI is higher values in the rainy season (spring or summer) and lower values in the dry season (autumn or winter) in northern Shaanxi Loess Plateau area, consistent with Chen et al. (2003). (4) Spatial changes in TVDI indicated that LSM of each watershed had different seasonal variation. In detail, TVDI in the northern watersheds increased rapidly from winter to spring, but in the south decreased from summer to autumn. In the centre and western watersheds, the increment of TVDI from winter to spring was similar to the decrement from summer to autumn. Similarly, the spatial variation of LSM was seasonal. Typically, in October, the variance of TVDI in most watersheds, especially in the north, reached a maximum. (5) Using the time series of MODIS data, we can determine the relationship between TVDI and land cover types in the Loess Plateau area. With respect to vegetative restoration in the Loess Plateau, considering the variability of water-retention of different land cover types, it is suggested that increasing the forest and sparse wooded areas in relatively wet regions, and increasing the grass areas and promoting land reclamation in dry areas will promote better ecological patterns, such as reduced erosion potential and less desertification.

The present results show that TVDI extracts moisture data, but the satellite-based TVDI metric cannot separate the soil moisture information in the case of a full canopy. A better land cover classification may help to derive moisture information according to the vegetative characteristics of each land cover type. More rigorous examination with concurring field data to the TVDI with attention to temporal and spatial variation would further improve the present paper.

\section{Acknowledgements}

This study was financially supported by the Key Project of the National Natural Science Foundation of China (Grant no. 40635028), the National Natural Science Foundation of China (Grant no. 40601001) and the National Science and Technology Support Program of China (Grant no. 2006BAD20B07). These supports are greatly appreciated. The Institute of Agricultural Resources and Planning in the Chinese Academy of Agricultural Sciences is gratefully acknowledged for kindly supplying the Terra/MODIS products. Two anonymous reviewers provided valuable comments that helped us to further improve the earlier draft of this paper were also appreciated. 


\section{Appendix A. Supplementary materials}

Supplementary data associated with this article can be found in the online version at doi:10.1016/j. jaridenv.2007.11.014.

\section{References}

Boegh, E., Soegaard, H., Hanan, N., Kabat, P., Lesch, L., 1998. A remote sensing study of the NDVI-Ts relationship and the transpiration from sparse vegetation in the Sahel based on high resolution satellite data. Remote Sensing of Environment 69 (3), 224-240.

Chen, Y.H., Li, X.B., Shi, P.J., Dou, W., Li, X., 2003. Intra-annual vegetation change characteristics in the NDVI-Ts Space: application to farming-pastoral zone in North China. Acta Botanica Sinica 45 (10), 1139-1145.

Francis, C.F., Thomes, J.B., Romero Diaz, A., Lopez Bermudez, F., Fisher, G.C., 1986. Topographic control of soil moisture, vegetation cover and land degradation in a moisture stressed Mediterranean environment. Catena 13, 211-225.

Friedl, M.A., Davis, F.W., 1994. Sources of variation in radiometric surface temperature over a tall grass prairie. Remote Sensing of Environment 48, 1-17.

$\mathrm{Fu}$, B.J., 1995. The spatial pattern analysis of agricultural landscape in the Loess area. Acta Ecologica Sinica 15 (2), $113-119$ (in Chinese).

Fu, B.J., Chen, L.D., 2000. Agricultural landscape spatial pattern analysis in the semi-arid hill area of the Loess Plateau, China. Journal of Arid Environments 44, 291-303.

Fu, B.J., Gulinck, H., 1994. Land evaluation in area of severe erosion: the Loess Plateau of China. Land Degradation and Rehabilitation $5,33-40$.

Fu, B.J., Wang, J., Ma, K.M., 1999. Effect of land use on soil water in Loess hill area. Science Foundation in China 13 (4), $225-227$ (in Chinese).

Fu, B.J., Chen, L.D., Ma, K.M., Zhou, H.F., Wang, J., 2000. The relationships between land use and soil conditions in the hilly area of the Loess Plateau in northern Shaanxi, China. Catena 39, 69-78.

Gao, B., 1996. NDWI-a normalized difference water index for remote sensing of vegetation liquid water from space. Remote Sensing of Environment 58, 257-266.

Gillies, R.R., Kustas, W.P., Humes, K.S., 1997. A verification of the 'triangle' method for obtaining surface soil water content and energy fluxes from remote measurements of the Normalized Difference Vegetation Index (NDVI) and surface radiant temperature. International Journal of Remote Sensing 18 (15), 3145-3166.

Goetz, S.J., 1997. Multisensor analysis of NDVI, surface temperature and biophysical variables at a mixed grassland site. International Journal of Remote Sensing 18 (15), 71-94.

Goward, S.N., Xue, Y., Czajkowski, K.P., 2002. Evaluating land surface moisture conditions from the remotely sensed temperature/ vegetation index measurements: an exploration with the simplified simple biosphere model. Remote Sensing of Environment 79, 225-242.

Hawley, M.E., Jackson, T.J., McCuen, R.H., 1983. Surface soil moisture on small agricultural watersheds. Journal of Hydrology 62 , 179-200.

Huete, A., Didan, K., Miura, T., Rodriguez, E., Gao, X., Ferreira, L., 2002. Overview of the radiometric and biophysical performance of the MODIS vegetation indices. Remote Sensing of Environment 83 (1-2), 195-213.

Jackson, T.J., Schmugge, T.J., 1991. Vegetation effects on the microwave emission of soils. Remote Sensing of Environment 36, $203-212$.

Jackson, R.D., Idso, S.B., Reginato, R.J., 1981. Canopy temperature as a crop water stress indicator. Water Resource Research 17 , $1133-1138$.

Jackson, T.J., Chen, D., Cosh, M., Li, F., Anderson, M., Walthall, C., Doriaswamy, P., Hunt, E.R., 2004. Vegetation water content mapping using Landsat data derived normalized difference water index for corn and soybeans. Remote Sensing of Environment 92, 475-482.

Justice, C.O., Vermote, E., Townshend, J.R.G., Defries, R., Roy, D.P., Hall, D.K., Salomonson, V.V., Privette, J.L., Riggs, G., Strahler, A., Lucht, W., Myneni, R.B., Knyazikhin, Y., Running, S.W., Nemani, R.R., Wan, Z.M., Huete, A.R., van Leeuwen, W., Wolfe, R.E., Giglio, L., Muller, J.P., Lewis, P., Barnsley, M.J., 1998. The Moderate Resolution Imaging Spectroradiometer (MODIS): land remote sensing for global change research. IEEE Transactions on Geoscience and Remote Sensing 36 (4), $1228-1249$.

Kogan, F.N., 1995. Application of vegetation index and brightness temperature for drought detection. Advances in Space Research 15 , 91-100.

Lambin, E.F., Ehrlich, D., 1996. The surface temperature - vegetation index space for land cover and land cover change analysis International Journal of Remote Sensing 17, 463-487.

Liu, W., Kogan, F.N., 1996. Monitoring regional drought using the vegetation condition index. International Journal of Remote Sensing 17, 2761-2782.

Mannstein, H., 1987. Surface energy budget, surface temperature and thermal inertia. In: Vaughan, R.A., Reidel, D. (Eds.), Remote Sensing Applications in Meteorology and Climatology. NATO Advanced Study Institutes Series. Series C, Mathematical and Physical Sciences, vol. 201. A. Reidel Publishing Inc., Dordrecht, the Netherlands, pp. 391-410.

McVicar, T.R., Jupp, D.L.B., 1998. The current and potential operational use of remote sensing to aid decisions on drought exceptional circumstances in Australia: a review. Agricultural System 57, 399-468. 
Moran, M.S., Clarke, T., Kustas, W.P., Weltz, M., Amer, S.A., 1994. Evaluation of hydrologic parameters in a semiarid rangeland using remotely sensed spectral data. Water Resources Research 30 (5), 1287-1297.

Nemani, R.R., Running, S.W., 1989. Estimation of regional surface resistance to evapotranspiration from NDVI and thermal IR AVHRR data. Journal of Applied Meteorology 28, 276-284.

Ng, E., Miller, P.C., 1980. Soil moisture relations in the southern California chaparral. Ecology 61, 98-107.

Penuelas, J., Filella, I., Biel, C., Serrano, L., Save, R., 1993. The reflectance at the $950-970 \mathrm{~mm}$ region as an indicator of plant water status. International Journal of Remote Sensing 14, 1887-1905.

Prihodko, L., Goward, S.N., 1997. Estimation of air temperature from remotely sensed surface observations. Remote Sensing of Environment 60 (3), 335-346.

Pyne, S.J., Andrews, P.L., Laven, R.D., 1996. Introduction to Wildland Fire, second ed. New York, Wiley.

Ran, Q., Zhang, Z.X., Zhang, G.P., Zhou, Q.B., 2005. DEM correction using TVDI to evaluate soil moisture status in China. Science of Soil and Water Conservation 3 (2), 32-36 (in Chinese).

Reynolds, S.G., 1970. The gravimetric method of soil moisture determination, III: An examination of factors influencing soil moisture variability. Journal of Hydrology 11, 288-300.

Sandholt, I., Rasmussena, K., Andersenb, J., 2002. A simple interpretation of the surface temperature/vegetation index space for assessment of surface moisture status. Remote Sensing of Environment 79, 213-224.

Sellers, P.J., Hall, F.G., Asrar, G., Strebel, D.E., Murphy, R.E., 1988. The first ISLSCP Field Experiment (FIFE). Bulletin of the American Meteorological Society 69 (1), 22-27.

Thornthwaite, C.W., 1948. An approach toward a rational classification of climate. Geographic Review 38, 55-94.

Tian, G.L., 1993. Estimation of Evapotranspiration and Soil Moisture and Drought Monitoring Using Remote Sensing in North China Plain. Space and Environment, IAF, Graz Austria, pp. 128-135.

Townshend, J., Justice, C., 2002. Towards operational monitoring of terrestrial systems by moderate-resolution remote sensing. Remote Sensing of Environment 83 (1-2), 351-359.

Tucker, C.J., 1979. Red and photographic infrared linear combinations for monitoring vegetation. Remote Sensing of Environment 8 , $127-150$.

Wan, Z., Wang, P., Li, X., 2004. Using MODIS land surface temperature and normalized difference vegetation index products for monitoring drought in the southern Great Plains, USA. International Journal of Remote Sensing 25 (1), 61-72.

Wang, P.X., Wan, Z.M., Gong, J.Y., Li, X.W., Wang, J.D., 2003. Advances in drought monitoring by using remotely sensed normalized difference vegetation index and land surface temperature products. Advance in Earth Sciences 18 (8), $527-533$ (in Chinese).

Yao, C.S., Zhang, Z.X., Wang, X., 2004. Evaluating soil moisture status in Xinjiang using the Temperature Vegetation Dryness Index (TVDI). Remote Sensing Technology and Application 19 (6), 473-478 (in Chinese). 